\title{
Uma Experiência Interdisciplinar na Formação Continuada de Professores da Rede Pública no PACTO pelo Fortalecimento do Ensino Médio
}

\author{
Una Experiencia Interdisciplinaria en la Formación Continuada de \\ Profesores de la Red Pública en el PACTO por el Fortalecimiento de la \\ Enseñanza Media
}

An Interdisciplinary Experience in the Continuing Education of Teachers of the Public Network in the PACT for Strengthening High School

\author{
Marília Nunes Dall'Asta ${ }^{1}$ \\ Elaine Corrêa Pereira ${ }^{2}$ \\ Celiane Costa Machado ${ }^{3}$
}

\begin{abstract}
Resumo
Este artigo tem como objetivo apresentar o resultado de uma experiência á formação continuada de professores desenvolvida no projeto Pacto pelo Fortalecimento do Ensino Médio, organizado pela Universidade Federal de Rio Grande-FURG. O projeto teve, como mentor, o Ministério da Educação e Cultura (MEC), tendo a parceria das Secretarias da Educação (SEDUC) e as Universidades Federais (IES), tendo como meta, realizar a formação de professores da rede pública. No desenvolvimento da experiência foram utilizadas as ideias compartilhadas como forma de reforçar e embasar a visão cientifica sobre o conhecimento da interdisciplinaridade, criando um conjunto de referências no processo da formação de professores evidenciando o acoplamento das áreas do conhecimento com suas tecnologias. Na miscigenação das ações cooperativas, houve um consenso geral de entendimento sobre o "ser interdisciplinar", estabelecendo um desafio aos professores a efetivarem ações imbricadas entre a Matemática, Linguagem e Artes Visuais, independente de suas áreas de formação, tendo como eixo comum o trabalho coletivo interdisciplinar. Na utilização do Origami ficou evidenciado o compartilhar, refletir, estudar, conhecer, intervir na formação do Pacto, fazendo com que não ficasse utópica, a realização das ações coletivas, fortalecendo o conhecimento, já existente, dos profissionais da educação, percebendo a importância do desempenho de atividades no cotidiano, tendo na interdisciplinaridade a projeção do compartilhamento de experiências e a superação de limitações identificadas.
\end{abstract}

Palavras-Chave: Formação Continuada; Pacto; Interdisciplinaridade e Origami.

\footnotetext{
${ }^{1}$ Mestre em Educação pela Universidade Federal de Santa Maria; Universidade Federal do Rio Grande, Rio Grande, Rio Grande do Sul, Brasil; dallastamarilia@gmail.com. Trabalho apresentado no I Seminário LatinoAmericano de Estudos em Cultura - SEMLACult, Foz do Iguaçu/PR, Brasil, 2017.

${ }^{2}$ Doutora em Engenharia de Produção pela Universidade Federal de Santa Catarina; Universidade Federal do Rio Grande, Rio Grande, Rio Grande do Sul, Brasil; elainepereira@ prolic.furg.br . Trabalho apresentado no I Seminário Latino-Americano de Estudos em Cultura - SEMLACult, Foz do Iguaçu/PR, Brasil, 2017.

${ }^{3}$ Doutora em Matemática pela Universidade Federal do Rio Grande do Sul; Universidade Federal do Rio Grande, Rio Grande, Rio Grande do Sul, Brasil; celianecmachado@gmail.com . Trabalho apresentado no I Seminário Latino-Americano de Estudos em Cultura - SEMLACult, Foz do Iguaçu/PR, Brasil, 2017.
} 


\begin{abstract}
Resumen
Este artículo tiene como objetivo presentar el resultado de una experiencia a la formación continuada de profesores desarrollada en el proyecto Pacto por el Fortalecimiento de la Enseñanza Media, organizado por la Universidad Federal de Rio Grande-FURG. El proyecto tuvo, como mentor, el Ministerio de Educación y Cultura (MEC), teniendo la asociación de las Secretarías de Educación (SEDUC) y las Universidades Federales (IES), teniendo como meta, realizar la formación de profesores de la red pública. En el desarrollo de la experiencia se utilizaron las ideas compartidas como forma de reforzar y basar la visión científica sobre el conocimiento de la interdisciplinaridad, creando un conjunto de referencias en el proceso de la formación de profesores evidenciando el acoplamiento de las áreas del conocimiento con sus tecnologías. En el mestizaje de las acciones cooperativas, hubo un consenso general de entendimiento sobre el "ser interdisciplinario", estableciendo un desafio a los profesores a realizar acciones imbricadas entre la Matemática, Lenguaje y Artes Visuales, independiente de sus áreas de formación, teniendo como eje común el trabajo colectivo interdisciplinario. En la utilización del Origami quedó evidenciado el compartir, reflexionar, estudiar, conocer, intervenir en la formación del Pacto, haciendo que no fuese utópica, la realización de las acciones colectivas, fortaleciendo el conocimiento, ya existente, de los profesionales de la educación, percibiendo la importancia del el desempeño de actividades en el cotidiano, teniendo en la interdisciplinaridad la proyección del intercambio de experiencias y la superación de limitaciones identificadas.
\end{abstract}

Palabras claves: Formación continua; Pacto; Interdisciplinariedad y Origami.

\begin{abstract}
This article aims to present the results of an experience of continuing teacher training developed in the Pact for Strengthening High School, organized by the Federal University of Rio Grande-FURG. The project had as a mentor the Ministry of Education and Culture (MEC), with the partnership of the Secretariats of Education (SEDUC) and the Federal Universities (IES), with the goal of conducting public teacher training. In the development of the experience, shared ideas were used as a way to reinforce and support the scientific vision on the knowledge of interdisciplinarity, creating a set of references in the process of teacher training, evidencing the coupling of the areas of knowledge with their technologies. In the miscegenation of the cooperative actions, there was a general consensus of understanding about the "interdisciplinary being", establishing a challenge for teachers to carry out imbricated actions between Mathematics, Language and Visual Arts, regardless of their areas of formation, having as a common axis the work collective interdisciplinary. In the use of Origami, it was evidenced to share, reflect, study, know, intervene in the formation of the Pact, making it not utopian, the accomplishment of collective actions, strengthening the already existing knowledge of education professionals, realizing the importance of performance of activities in the daily life, having in the interdisciplinarity the projection of the sharing of experiences and the overcoming of identified limitations.
\end{abstract}

Keywords: Continuing Education; Covenant; Interdisciplinarity and Origami.

\title{
1. Introdução
}

Nas últimas décadas é crescente na Educação a preocupação dos órgãos públicos com o trabalho desenvolvido em sala de aula, em especial, no Ensino Médio, relativo ao desempenho dos professores. Nesta preocupação surgem questionamentos tais como: qual a exigência da sociedade em relação à formação do jovem cidadão para atuação na comunidade em que vivem? Qual a formação que possui o professor para atuar na formação dos jovens na sociedade? Como valorizar o profissional da Educação? Estas preocupações, entre outras, contemplam, também, os conteúdos disciplinares e as metodologias aplicadas cotidianamente na escola. 
Neste sentido este artigo tem como objetivo apresentar o resultado de uma experiência realizada entre março de 2014 a julho de 2015, referente à formação continuada de professores desenvolvida no projeto Pacto pelo Fortalecimento do Ensino Médio.

O Pacto teve como meta a realização de ações de Formação Continuada de Professores, da rede pública, visando uma Educação de Qualidade. Nesta formação o Governo Federal, responsável pelo projeto, através do MEC, constatou que para conseguir as metas sobre o Fortalecimento do Ensino Médio (EM), era necessário e imprescindível focalizar no professor como o executor da integralidade formativa do educando deste EM.

Destaca-se que o Pacto tem como objetivo:

Art. $2^{\circ}[\ldots]$ promover a valorização da formação continuada dos professores e coordenadores pedagógicos que atuam no Ensino Médio público, nas áreas rurais e urbanas, em consonância com a Lei de Diretrizes e Base da Educação Nacional (Lei $\mathrm{n}^{\circ} 9394$ de 20 de dezembro de 1996 - LDB) e as Diretrizes Curriculares Nacionais do Ensino Médio (Brasil, 2012).

O Pacto foi realizado em parceria com as Universidades Federais de Ensino Superior (IES), Secretarias da Educação (SEDUC) e Coordenadorias Regionais da Educação (CRE). Inicialmente, foi observado à necessidade em apoiar os professores no que se referia, não apenas a revisão de conhecimentos acadêmicos, mas em uma renovação, de forma interdisciplinar, sempre que possível direcionado ao trabalho em sala de aula. Também foi sugerido um estudo sobre as leis, resoluções, decretos e portarias, contendo a estruturação das normas para o desenvolvimento do Pacto.

Pela Portaria do MEC, $\mathrm{n}^{\mathrm{o}} 1.140$, de 22 de novembro de 2013, em sintonia com a Resolução $n^{\circ} 51 / 2013$, as ações foram desenvolvidas pela SEDUC e pelas IES. As funções desempenhadas por cada componente na organização Pacto estão descritas a seguir, conforme (Brasil, 2012):

O Coordenador Geral (Professor IES) - organizador de gestão e execução do projeto Pacto, ficando em permanente contato como o MEC/SEDUC;

O Coordenador Adjunto (Professor IES) - apoia ao Coordenador Geral participa das reuniões junto a SEDUC e/ou MEC na impossibilidade do Coordenador Geral;

O $\underline{\text { Supervisor }}$ (Professor da SEDUC) - deve ser professor ou coordenador pedagógico. Tem função de apoio entre a coordenação geral e os professores;

O Formador (Professor da IES). - responsável pela formação dos orientadores de estudo. Realiza a Formação Continuada de acordo com os conteúdos indicados nos Módulos de Estudos fornecidos pelo MEC; 
O Orientador de Estudo (Professor da Rede) - professor da escola, formado em uma licenciatura, tendo no mínimo dois anos de exercício na docência ou na coordenação pedagógica. O trabalho a ser realizado é o de multiplicador, da formação recebida.

Além das resoluções e metas do Pacto, para as duas Etapas de Formação, o governo federal forneceu um material comum para todo o território nacional, sendo que as temáticas estavam descritas nos cadernos de formação, com sugestões de ações e atividades comuns, indicadas para todo o território nacional (Brasil, 2013). O material de estudo, em número de seis cadernos para a Etapa I e de cinco para a Etapa II, teve a sua formatação e elaboração do processo técnico, sob a responsabilidade do Setor de Educação da Universidade Federal do Paraná (UFPR). A Etapa I compreendeu um estudo sobre as Políticas Públicas Educacionais, Formação Docente e Interdisciplinaridade, enquanto que a Etapa II deu ênfase as práticas educativas a partir de cada uma das áreas do conhecimento.

Mantendo a base de estudos sugeridos pelas normas do Pacto, especialmente no aprender a conviver focando a interdisciplinaridade do trabalho coletivo temos para Fazenda (2013):

[...] na busca do refletir sobre a ação do docente de forma interdisciplinar, é importante pensar no professor como elemento central, principalmente no sentido de lhe permitir apropriar-se dos seus processos formativos, articulando-os enquanto desenvolvimento de sua identidade profissional (p.36).

Com o refletir nos dizeres da referida autora, nos estudos realizados, nas experiências compartilhadas e nas atividades desenvolvidas no Pacto temos, então, os questionamentos: como se realizaram as ações interdisciplinares? Como foram organizadas as sugestões para o desenvolvimento de um trabalho coletivo? No Pacto como se sistematizou uma proposta interdisciplinar em sala de aula? Discutiremos esses questionamentos com base nas ações desenvolvidas durante a formação realizada pela Universidade Federal do Rio Grande FURG.

\section{As ações Interdisciplinares no Pacto - FURG}

O uso do termo interdisciplinaridade em diferentes situações é uma prática que se acentuou com estudos e pesquisas realizadas por diferentes grupos de estudiosos desde o no ano de 1970. Com a adesão das Universidades Federais ao Exame Nacional do Ensino Médio (ENEM), a interdisciplinaridade tornou-se destaque para este tipo de avaliação. Pelo ENEM, verificamos ser uma avaliação para além da forma disciplinar como sempre ocorria, mas 
numa dimensão maior, conduzindo o conhecimento a entrelaçar-se não apenas a um programa conteudista único, mas a outros, que possuíssem objetivos comuns tanto de formação de valores, quanto de informações necessárias ao desenvolvimento integral de cidadania. Neste sentido surge o compartilhar interdisciplinar.

Adotando-se uma nova visão sobre como as áreas do conhecimento podem ser aglutinadas entre si, temos o reconhecimento de que a interdisciplinaridade necessita ser aceita, estudada com profundidade e analisada, detalhadamente, sobre o porquê desta prática inovadora. Então, conhecer a essência interdisciplinar torna-se importante na construção do saber, desde que não se fique apenas na prática empírica, mas que esta prática se estenda ao desenvolvimento curricular, renovação da didática utilizada e muito especialmente, no reconhecimento das formas de entrelaçamento dos saberes desenvolvido.

Por interdisciplinaridade temos nos dizeres de Fazenda (2013):

Inclui desafios de diferentes ordens: teórica, pessoal, metodológica. Neste contexto a interdisciplinaridade tem um papel profundo nas histórias de vida e princípios que poderão alicerçar intervenções na formação de professores. Ela é definida como uma interação existente entre duas ou mais disciplinas, podendo ser da simples comunicação das ideias até a integração mútua dos conceitos epistemológicos, terminologia do procedimento dos dados e da organização do ensino relacionandoos (p.29).

Muitos professores sentem-se impotentes diante do desafio em apresentar conhecimentos interdisciplinarmente, de forma contextualizada, em suas práticas escolares, pois alegam desconhecer a dimensão epistemológica que orienta o campo do saber compartilhado. Seguindo este raciocínio de desconhecimento, fica evidente a impossibilidade de despertar no educando uma visão globalizada da construção e aplicação do saber no cotidiano uma vez que o professor também não se sente preparado para realizar um trabalho no coletivo.

É preciso que o compartilhar no coletivo contribua para a produção de novos saberes, mais organizados e que ao mesmo tempo sirvam para a teorização sobre o que seja interdisciplinaridade. Segundo Fazenda (2012):

[...] a interdisciplinaridade é essencialmente um processo que precisa ser vivido e exercido. [...] um movimento interdisciplinar que é estabelecido com novas e melhores parcerias, onde o conhecimento interdisciplinar quando reduzido a ele mesmo empobrece, e quando socializado adquire mil formas inesperadas. (p.12).

Neste momento, a Educação, evidencia uma preocupação em manter uma relação entre ideias e realidade; educador e educando; teoria e ação surgindo, então, com Pacto uma 
possibilidade de formação docente interdisciplinar. E é neste sentido que se quer apresentar o projeto Pacto, desenvolvido para todo território nacional, especificamente, realizado pela FURG.

O desenvolvimento do Pacto na FURG iniciou em março de 2014 com leituras, reflexões e pesquisas sobre o suporte teórico da proposta focada nas leis e decretos, além do papel desenvolvido por cada setor que compõe o projeto. Este suporte teve seu embasamento no material enviado pelo MEC a todas as universidades federais que aderiram a esta formação para professores da rede pública.

Destacamos a participação das escolas nos encontros pedagógicos, como forma de unirem-se nas organizações escolares em torno de objetivos e concepções sobre: o que se quer formar e para quem servirá esta formação?

$\mathrm{Na}$ apresentação dos tópicos de estudo do Pacto, foram discutidos alguns pontos de entrelaçamento entre as áreas do conhecimento. Nesta discussão alguns professores demonstraram dificuldade em expor suas experiências e ações desenvolvidas no coletivo. Por esta razão o trabalho desenvolvido pelos Formadores precisou ser discutido intensamente para que se obtivesse uma proposta que oportunizasse uma aprendizagem de qualidade. Esta ocorrência, sem dúvida foi um desafio tanto para os formadores quanto para os orientadores de estudo.

A forma de como apresentar os conteúdos na área de atuação provocou um questionamento sobre o que se entende por aprendizagem e conhecimento que constituem uma base disciplinar. Neste momento, surgiram indagações sobre o que é um trabalho interdisciplinar e qual ou quais as áreas que propiciarão a concretização do alcance dos objetivos propostos no Pacto.

Nesta situação, foi necessário superar a problemática clássica do ensino, qual seja a concretização de ideias em ação, para não se criar apenas um novo modismo em educação. Desse modo foram surgindo outros questionamentos tais como: trabalhar a interdisciplinaridade nas escolas onde professores não foram motivados a conhecerem o tema e seu significado é importante? É necessária uma mudança na prática escolar quando tudo está organizado e dando certo?

Estas foram algumas das perguntas que não possuíam respostas imediatas e sim reflexões que estimulavam a pesquisarem formas que possibilitassem a determinar ações aplicadas, com metodologias diferenciadas que proporcionasse um entrelaçamento entre os campos das diferentes áreas do conhecimento. 
Neste emergir de atitude e consciência de que trabalhando na forma interdisciplinar o professor produz conhecimento útil, interligando a teoria e a prática, estabelecendo relações entre o conteúdo e a realidade social escolar. Nesta perspectiva apresentamos a seguir uma prática interdisciplinar envolvendo a Matemática, Artes Visuais e a Linguagem.

Para desenvolvimento deste trabalho utilizamos uma folha branca de papel tamanho A4, na qual realizamos a confecção da dobradura das peças do "Tangram" com o grupo de Orientadores de Estudo num dos encontros de Formação. Após a realização da dobradura, os professores coloriram as peças e então foram desafiados a identificarem as formas geométricas ali destacadas; os diferentes tipos de retas e outros entes geométricos primitivos.

Depois de conhecido o 'Tangram' foi apresentado um novo material em madeira com as sete peças, onde os professores em duplas identificaram as mesmas e formaram algumas figuras utilizando todas ou somente algumas delas. Depois deste reconhecimento inicial e montagem de quadrados, retângulos e triângulos, foi sugerido aos grupos que calculassem áreas e perímetros das figuras formadas. As peças podem ser identificadas pelas Figuras 1, 2 e 3.

Fig. 1 Tangram completo

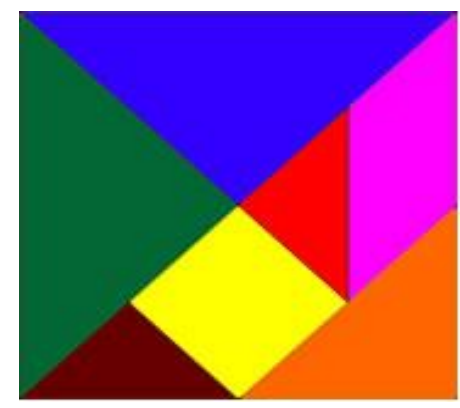

Fonte: Autoria Própria
Fig. 2.Tangram Tridimensional

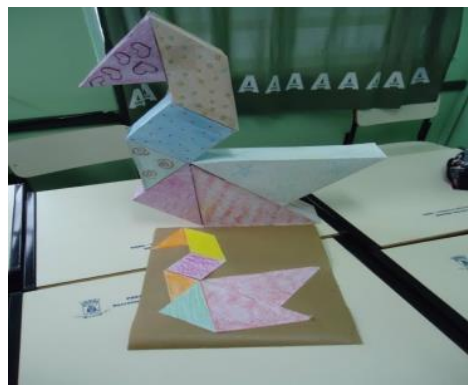

Fonte: Autoria Própria
Fig. 3 Peças do Tangram

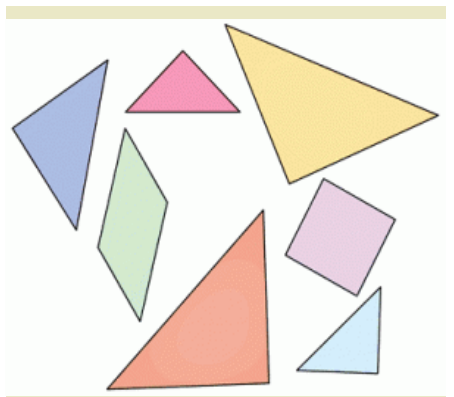

Fonte: Autoria Própria

Nestas operações o grupo sugeriu a ideia da descrição textual sobre os trabalhos desenvolvidos entrando a colaboração das Artes Visuais, Linguagem e a Matemática. Nesta conclusão foi verificada a possibilidade de apresentações nos Seminários Integrados e Feira de Ciências com trabalhos dos alunos das escolas municipais e estaduais.

Como segunda atividade prática os professores confeccionaram o octógono estrelado $^{5}$, com dobraduras de oito paralelogramos para então formarem o polígono conforme Figura 4.

\footnotetext{
${ }^{4}$ Peças geométricas, invento chinês, do séc. XIX. Em chinês, o Tangram conhecido como Chi Chiao, ou "as sete peças inteligentes". (Genova, 2009)

${ }^{5}$ Polígono regular de oito lados congruentes (Genova, 2009).
} 
Fig.4 octógono estrelar.

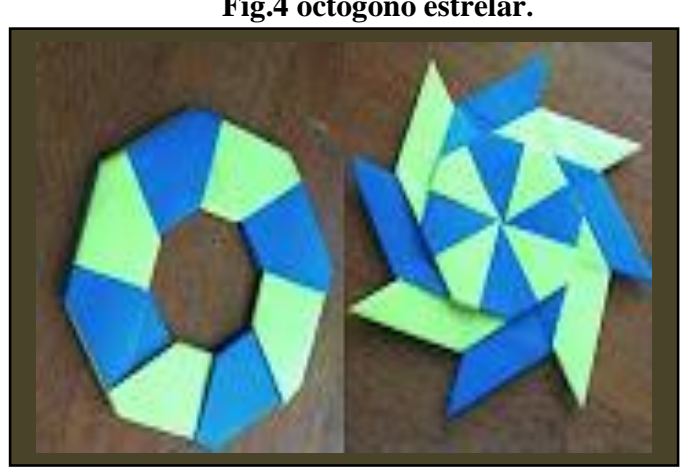

Fonte: Autoria Própria

Nesta ocasião alguns professores manifestaram o desejo de conhecerem outras atividades de dobraduras e confecção de novos trabalhos em origami ${ }^{6}$. Os trabalhos realizados criaram espaço de reflexão, pesquisa e discussão acerca do uso de materiais concretos imbricados num ensino interdisciplinar incorporando leituras de imagens, análise visual e sensorial, a alfabetização e atividades lúdicas de criação e construção de materiais os quais podem facilitar o aprendizado de diferentes conceitos, pois segundo MATURANA (1993):

(...) a tarefa do educador é criar um espaço de convivência ao qual se convida o outro, de modo que o outro esteja disposto a conviver conosco, por certo tempo, espontaneamente. E nesta convivência ambos, educador e aprendiz, irão se transformar de maneira congruente. (p.32).

O estudo de algumas ações específicas, quando bem planejadas não ficam restritas a uma única área do conhecimento com as suas tecnologias, mas possibilitam a realização de um trabalho coletivo e construtivo com professores e estudantes. Percebemos que as ações sobre o fazer/fazendo motivaram os professores à constatação de que a Formação Continuada de Professores é possível desde que todos se sintam imbuídos da ideia de que ser interdisciplinar é um trabalho coletivo e colaborativo onde cada professor reveja a sua prática e redescubra os seus talentos.

Outras ações foram desenvolvidas ao longo do Pacto na FURG podendo ser citadas leituras de textos com interpretação teatral, descritivas, pesquisas temáticas; Mostras de Produção Ensino Médio Integrado; confecção origamistas entre outros. Nestas realizações foi necessário um chamamento ao trabalho de interação entre a teoria e prática, pois interdisciplinaridade não se ensina, nem se aprende, apenas vive-se, exerce-se (Fazenda,

\footnotetext{
${ }^{6}$ Origami (ori "dobrar", e kami, "papel”) é a arte e brincadeira secular japonesa de dobrar o papel, criando representações de determinados seres ou objetos com as dobras geométricas. (Genova, 2009)
} 
2011, p.94). Assim temos que a interdisciplinaridade exige uma dedicação, engajamento e aceitação tanto pessoal como coletiva.

As ações foram sempre selecionadas e estudadas, anteriormente, na temática Interdisciplinar para que não houvesse improvisações e circunstâncias inesperadas. Neste aspecto chegamos à conclusão de que a interdisciplinaridade só se efetuará quando as instituições, com toda a sua infraestrutura, se conscientize sobre o valor construtivo e motivador de professores e alunos no ambiente escolar. Citando Fazenda (2011) temos que:

\footnotetext{
“(...) a prática da interdisciplinaridade exige uma nova articulação de espaço e tempo que favorece os encontros e trabalhos em pequenos grupos, assim como os contatos individuais entre professores e estudantes". (p.95).
}

A formação continuada do educador perpassa por diversos fatores como conhecer a realidade do aluno, identificar a aplicação cotidiana do conteúdo a ser desenvolvido; o conhecimento empírico e o trabalho coletivo entre professores, e outros que ao serem pesquisados contribuirão para que se chegue a um ensino de qualidade. Essa mudança pode acontecer num ensino interdisciplinar, que de acordo com Japiassú (1976):

[...] impõe a cada especialista que transcenda sua própria especialidade, tomando consciência de seus próprios limites para acolher as contribuições das outras disciplinas. Uma epistemologia da complementaridade, ou melhor, da convergência, deve, pois, substituir a da dissociação. À totalização incoerente de palavras não compatíveis entre si, deve suceder a busca de uma palavra de unidade, expressão da reconciliação do ser humano consigo e com o mundo. Bem entendido, essa unidade não é atualmente dada; não existe ainda se não na esperança, na perspectiva de um olhar escatológico, fixo sobre esse ponto do horizonte em que as paralelas se encontram. (p.26).

Neste sentido a postura interdisciplinar exige conhecimento para entrelaçá-lo as diversas disciplinas e para tanto se faz necessário que o professor/educador seja competente, dinâmico e eficaz dando, desta forma, mais ênfase ao processo de aprendizagem.

\section{Considerações finais}

O Pacto pelo fortalecimento do Ensino Médio possibilitou o desenvolvimento de práticas interdisciplinares voltadas ao trabalho coletivo. Durante a experiência os professores da rede pública vivenciaram atividades que possibilitaram integrar diferentes áreas do conhecimento como: Matemática, Artes Visuais e Linguagem.

A prática Origamista suscitou a criticidade e a criatividade quanto ao seu potencial em práticas de sala de aula. A partir do Tangram foi explorada a imaginação na construção de 
figuras como: tsuru (grou $)^{7}$, o barco, o peixe, a casa, entre outras. Além disso, por meio da escrita os professores foram desafiados a relatar, sobre as ações sugeridas. Alguns professores descreveram suas dificuldades, outros contribuíram com textos que falavam da "beleza" de seus trabalhos, em quanto que outros, compuseram poemas referentes ao reconhecimento da habilidade manual em Origami.

Neste emergir de atitude e consciência de que trabalhando na forma interdisciplinar o professor produz conhecimento útil, interligando a teoria e a prática, estabelecendo relações entre o conteúdo e a realidade social escolar. Esta ocorrência foi um desafio para todos os participantes da formação devido a mudança necessária quanto a forma de envolvimento e aceitação da coletividade da aplicação em sala de aula sobre o ensinar/aprendendo e do fazer/fazendo.

Assim, percebemos que as ações desenvolvidas permitiram um ambiente de estudos, em que o trabalho coletivo oportunizou reflexões sobre a prática docente e a sua aplicabilidade no cotidiano. A valorização do "outro" no sentido de compartilhamento de novas ideias contribuindo para uma formação interdisciplinar.

\section{Referências}

BRASIL. Sec. da Educação Fundamental. Parâmetros Curriculares Nacionais: Matemática $1^{\text {a }}$ Ed. Brasília MEC/SEF, 1998.

BRASIL, MEC. Expansão da Rede Federal de Educação Profissional Científica e Tecnológica. 2009.

CORRÊA. Gilka. A Arte de dobrar papel. $2^{\text {a }}$ Ed. Editora FURG. Rio Grande- RS. 1995.

DELAZZANA, Ana Rosa. Interdisciplinaridade: um olhar sobre a prática docente. Centro Universitário Franciscano- Unifra, Santa Maria-RS. 2003.

FAZENDA, Ivani C. O que é Interdisciplinaridade? Ed. Cortez, São Paulo. SP. 2008. Práticas Interdisciplinares na escola. Ed. Cortes $12^{\mathrm{a}}$ ed. São Paulo, 2011. Interdisciplinaridade: História, Teoria e Pesquisa. Papirus Ed. Campinas. Formação de Docentes Interdisciplinares Ed. CRV. Curitiba - PR. 2013.

\footnotetext{
7 Tradição chinesa (grou) ave associada à música (Paz do mundo), da família dos gruídeos, encontradas em zonas pantanosas de todo mundo, com exceção da América do Sul, com pernas e pescoço longos, bico reto e com penas brancas. (Genova, p.83-87. 2009).
} 
RELACult - Revista Latino-Americana de Estudos em Cultura e Sociedade

GENOVA Carlos. Origami, Dobras, Contas e Encantos. Ed. Escrituras, $2^{\text {a }}$ Edição. SP. 2009.

JAPIASSÚ, H. Interdisciplinaridade e patologia do saber. Ed. Imago Rio de Janeiro. 1976.

MATURAMA, H. Uma nova concepção de aprendizagem. In: Dois pontos, v. 2, nº 15, 1993.

MINISTÉRIO DA EDUCAÇÃO E CULTURA (MEC):- Portaria n⿳ 1.140, de 22/11/ de 2013.

MORAES, Maria Cândida. O Paradigma Educacional Emergente- 16ª ed. Campinas. SP. Papirus, 2012.

MINISTÉRIO DA EDUCAÇÃO. Documento orientador das ações de formação continuada de professores e coordenadores pedagógicos do Ensino Médio em 2014.

POMBO, O. O conceito de interdisciplinaridade e conceitos afins. Lisboa, Tex to Editora, 1993.

PARECER CEB/CNE n 5/2011- MINISTÉRIO DA EDUCAÇÃO E CULTURA/MEC. 